underdeveloped and had menstrual irregularity, and three (including our Case 1) showed an infantile uterus with amenorrhoea or oligomenorrhoea. These are the only symptoms which might conceivably be put down to hypothalamic damage. Records of histological examination of brain stem and hypothalamus are scanty. Rossi (1893), quoted by Schlezinger and Goldstein, described areas of degeneration subcortically, including the basal ganglia; and Wichtel (1943), cited by the same authors, reported degenerative change in the dorsal vagus and dentate nuclei, but normal basal ganglia and tuber cinereum. Köhne (1941) demonstrated normal supraoptic and paraventricular nuclei. The pituitary gland showed only an excess of eosinophil cells. There is thus little or no positive evidence in favour of the hypothesis of neurogenic diabetes.

\section{Diabetic Myelopathy}

As Friedreich's ataxia precedes the onset of diabetes mellitus, and is unlike any recognized neurological complication of it, theories of diabetic myelopathy need not receive serious consideration.

\section{Dysbiotrophy}

Endocrine disturbances in Friedreich's disease are almost always due to hypofunction of one or more glands of internal secretion-for example, myoedema, genital infantilism (Curtius et al. ; Schlezinger and Goldstein). As diabetes can be a manifestation of islet-cell hypofunction, it can be regarded as analogous to these and other non-neurological dysbiotrophies that occur, such as spina bifida, supernumerary digits, etc. The occurrence of some of these conditions, particularly the endocrine disturbances, may be determined by the genetic milieu of the ataxia-bearing gene, thus providing cases analogous to those with diabetes mellitus and Friedreich's ataxia.

\section{Summary}

Cases of Friedreich's ataxia and diabetes occurring in siblings are described; the previous literature is reviewed and theories of causation are discussed. Of these, the hypothesis that the combination is either a hereditary syndrome or an effect determined by the genetic milieu of the ataxia-bearing gene seems most satisfactory.

We are indebted to Dr. C. N. Armstrong for his helpful criticism and suggestions; to Mr. David F. Smith for his report on the pelvic organs; to Dr. A. C. Crooke for his estimation of the urinary 17-ketosteroids; to Miss U. Phillip for help with the genetic aspects of this paper; and to Dr. Julia Bell for reading the manuscript.

AdDEndum.- Since this paper was submitted for publication Dr. H. A. Dewar has kindly drawn our attention to two further sisters. One, aged 16 , has recently been under his care at the Royal Victoria Infirmary, Newcastle-upon-Tyne. She has mild ataxia, optic atrophy, and diabetes mellitus requiring insulin for its control. Her sister died in diabetic coma at the age of 19 , and is said to have-had ataxia and optic atrophy as well.

\section{REFERENCES}

Alpers, B. J.. and Waggoner, R. W. (1929). Arch. Neurol. Psychiat., Chicago, 21, 47.

Bell, J., and Carmichael. E. A. (1939). Treasury of Human Inheritance, vol. 4. part 3. Cambridge Univ. Press, London.

Bernard. C. (1855). Quoted in Best and Taylor's Physiological Basis of Medical Practice. 4th ed., 1945, p. 590. Baillière, Tindall and Cox, London.

Clark, W. E. Le Gros. et al. (1938). The Hypothalamus. Oliver and Boyd, Edinburgh.

Curtius, F., Störring. F. K., and Schönberg, K. (1935). Z. ges. Neurol. Psychiat., 153, 719 .

Dassen, R., Soto Romay, R., and Fustinoni, O. (1939). Sem. méd., B. Aires, 1,1256

Gates, R. R. (1946). Human Genetics, p. 546. Macmillan, New York.

Köhne, G. (1941). Dtsch. med. Wschr.. 67, 177

Lawrence. R. D. (1944). The Diabetic Life. 13 th ed. Churchill, London. (1951). British Medical Journal, 1, 373.

Mollaret, P. (1929). La Maladie de Friedreich. Lahure, Paris

Richards, C. E. (1946). It E. P. Joslin's Treatment of Diabetes Mellitus. 8th ed., p. 572 . Kimpton, London.

Schlezinger, N. S., and Goldstein, K. (1940). N.Y. St. J. Med., 40, 415

Schloss, J.' (1932). Dtsch. Z. Nervenheilk., 125, 201

Segall, G. (1948). J. Hered., 39, 228

\section{TIME OF ERUPTION OF PERMANENT TEETH IN BRITISH CHILDREN IN 1947-8}

\author{
BY
}

\section{E. M. B. CLEMENTS, M.B., B.S.}

E. DA VIES-THOMAS, M.R.C.S., L.R.C.P. L.D.S. R.C.S.

AND

\author{
KATHLEEN G. PICKETT, B.Sc. \\ (From the Department of Anatomy, University of \\ Birmingham)
}

The most recent study of the times of eruption of the permanent teeth in British children is the survey made by Ainsworth in 1925 . The object of the present paper is to bring the subject up to date, both by the assembly of new data and by the use of modern methods of analysis. Graphical techniques have usually been employed for estimating the mean eruption times of human teethfor summaries of the data see Schultz (1934), Dahlberg and Maunsbach (1948), and Gödény (1951). Dahlberg and Maunsbach, and Gödény, have based their own analyses upon the observation of Klein, Palmer, and Kramer (1937) that the frequencies of erupting teeth at successive ages follow the normal probability function. The precision of the staţistical methods for analysing integral responses of this function has been greatly improved over the past twenty years by the development of probit analysis (see Finney, 1947), and it is now possible to specify the statistical error of the estimates.

This paper is based on the analysis of dental observtions made during the course of the Birmingham Anthropometric Survey on 1,427 boys and 1,365 girls attending elementary schools. The children, who ranged in age from 5 to 13 years, were unselected and were drawn from 87 infant, junior, and secondary modern schools representing all types of area in the City of Birmingham.

\section{Survey}

Dental Examination.-The children were examined by one observer throughout (E.D.-T.). Examination was made in a good light with a dental mirror and probe. The observations were dictated to a clerical assistant, who recorded the findings on a standard form. Unerupted and extracted teeth were recorded as not present. The number of teeth extracted during the period of eruption will be very small, and will not have affected the analysis materially. A tooth was classified as erupted as soon as the gum was pierced. Clinical observations on the teeth were also recorded, but these have not been analysed in this paper.

Social and Anthropometric Data.-The Birmingham Anthropometric Survey recorded the occupation of either the father or the family's chief wage-earner. This information was coded into the appropriate socio-economic classification of the Registrar-General by reference to the Classification of Occupations. Class I comprises the professional, Class II the intermediate, Class III the skilled, Class IV the semi-skilled, and Class $\mathrm{V}$ the unskilled occupations. The development of puberty was assessed and scored on a fourpoint scale, using a scheme based on the classification proposed by Greulich et al. (1942). The age in months was recorded from the school records to the month below-that is, the age reached. The mean eruption times which are presented have not been adjusted for this grouping. At the examination an index number was allocated to each child to identify both the child and its school. 


\section{Combination of the Dental and Anthropometric Surveys}

The index number allocated to a child in the anthropometric survey was used in the dental survey. This common index number has linked the two surveys and has been the means of associating the information collected in each.

The records of the dental survey were coded into a numerical form suitable for punching into standard 80column Hollerith cards. The basis of this coding was that each column represented a tooth, and permitted up to 12 subdivisions. One of these was used to represent each of the possible classes of "absent" and "present" teeth, combined with observations on the incidence of caries.

A set of punch cards was prepared by a mechanical "reproducer" from the master cards of the Birmingham Anthropometric Survey to include only the index number, the age, and other coded information, the punches being made only in the first 19 columns. These cards were passed through" a "mechanical interpreter" which printed the index number on the card so that it was easily legible. These "reproduced" punch cards were then matched with the coded dental records, and the dental information read from the records was punched into the remaining columns.

The last preparatory procedure was carried out only to facilitate the computing, and consisted in converting the ages, so far recorded in months, into periods of a quarter of a year by grouping them in threes. The different groups were numbered in numerical order-for example, the ages, 060, 061, 062 (in months) were all numbered 01 (first quarter year) and so on. Each group had the number punched mechanically into the cards. The various manual steps in the coding and punching have been verified at each stage.

\section{Statistital}

A preliminary tabulation was made of the number of boys and girls in each age group. The number of erupted teeth in each group was then tabulated for each tooth. The probability of observing erupted teeth in each age group was computed from these data. These probabilities were graphed for all the teeth in the right lower jaw. They were transformed into probit values, and these were also

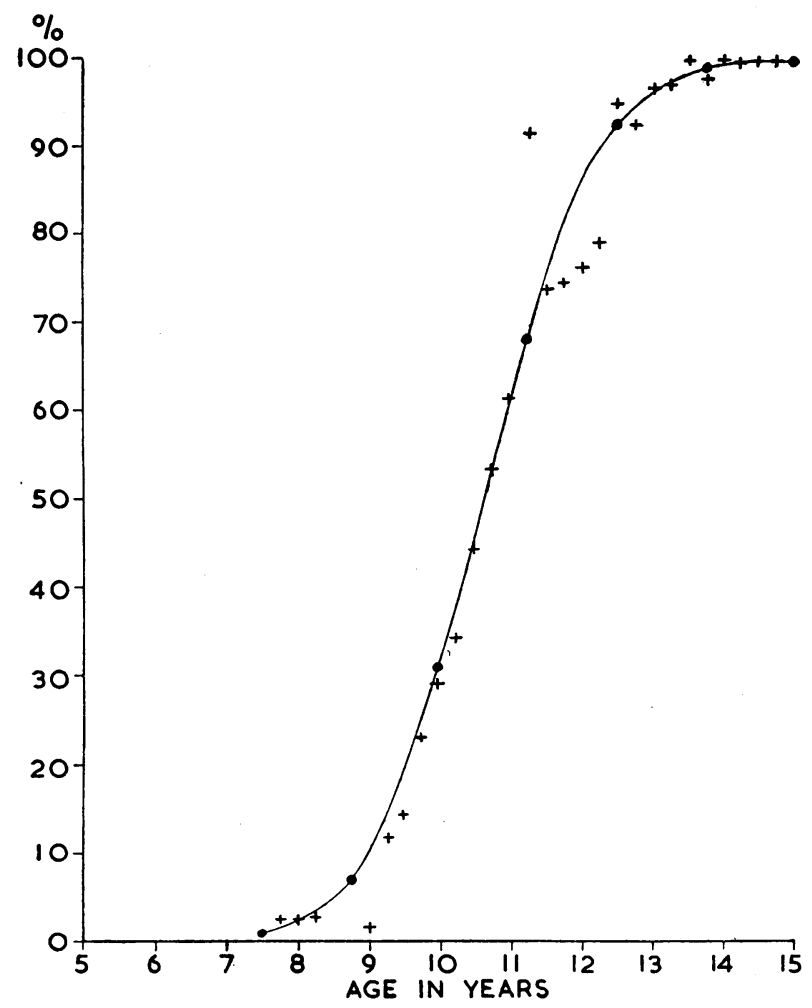

Chart showing the observed probability of eruption of boys' lower right canine teeth at different ages. graphed. The best-fitting straight line was fitted to these points, and from this line the corrected probit values were read off and transformed into probabilities. These corrected values were plotted on to the original graphs, and were found to smooth the observed data well. These findings indicate that the normal probability function will form the basis of a satisfactory analysis. As an example the probability of finding erupted lower canine teeth at different ages is shown in the Chart, and the smooth probability curve has been fitted in the manner described.

The analysis has been made by the probit method. The computations were based on the observed probabilities of finding the teeth erupted at various ages. The technique used was that devised by Black (1950), and the coefficients were corrected for the effects of grouping by the technique of Tocher (1949). Errors of estimate for the various statistics have been computed, and the various tests of significance have been made using a " $t$ " test. There is no evidence of heterogeneity of departure from the fitted probit lines. In the main samples, too, in which the development groups and social classes are pooled, the values of " $\mathrm{g}$ " are all less than 0.1 , and all except two of them are less than 0.03 .

\section{Results}

For convenience the following abbreviations have been used in reporting the findings : $I_{1}$ for the central incisor tooth; $\mathrm{I}_{2}$ for the lateral incisor tooth; $\mathrm{C}$ for the canine tooth ; $\mathrm{Pm}_{1}$ for the first premolar tooth; $\mathrm{Pm}_{2}$ for the second premolar tooth; $\mathbf{M}_{1}$ for the first molar tooth; $\mathbf{M}_{2}$ for the second molar tooth. No erupted third molar tooth was seen.

Mean Eruption Times of the Teeth.-The data for the teeth of the right upper and lower jaws have been examined in detail, and these form the basis of the various comparisons which have been made. The mean eruption times of the teeth in the upper and lower jaws are given in Table I for both sexes, with the standard error and the $5 \%$ and $95 \%$ fiducial limits of the mean. The statistics presented in Table $I$ are based on a relatively heterogeneous

TABLE I.-Mean Eruption Times, Standard Errors, and the 5\% and $95 \%$ Limits of the Mean, of the Teeth in the Right Upper and Lower Jaws

\begin{tabular}{|c|c|c|c|c|c|c|c|c|c|}
\hline \multirow{3}{*}{\multicolumn{2}{|c|}{ Tooth }} & \multicolumn{4}{|c|}{ Boys } & \multicolumn{4}{|c|}{ Girls } \\
\hline & & \multirow{2}{*}{$\begin{array}{c}\text { Mean } \\
\text { in } \\
\text { Months }\end{array}$} & \multirow{2}{*}{ S.E. } & \multicolumn{2}{|c|}{$\begin{array}{l}5-95 \% \text { Limit } \\
\text { of Mean }\end{array}$} & \multirow{2}{*}{$\begin{array}{c}\text { Mean } \\
\text { in } \\
\text { Months }\end{array}$} & \multirow{2}{*}{ S.E. } & \multicolumn{2}{|c|}{$\begin{array}{l}5-95 \% \text { Limit } \\
\text { of Mean }\end{array}$} \\
\hline & & & & Upper & Lower & & & Upper & Lower \\
\hline \multicolumn{10}{|c|}{ Upper Jaw } \\
\hline $\begin{array}{l}\mathrm{Pm}_{1} \\
\mathrm{Pm}_{2} \\
\mathbf{M}_{1} \\
\mathbf{M}_{2}\end{array}$ & $\begin{array}{l}. \\
\cdots \\
\cdots \\
\cdots \\
\cdots\end{array}$ & $\begin{array}{r}84.13 \\
98 \cdot 17 \\
137.56 \\
124.96 \\
138 \cdot 22 \\
73.29 \\
143.67\end{array}$ & $\begin{array}{l}0.71 \\
0.74 \\
0.92 \\
1 \cdot 12 \\
1.13 \\
0.78 \\
0.94\end{array}$ & $\begin{array}{r}85 \cdot 52 \\
99 \cdot 62 \\
139 \cdot 37 \\
127 \cdot 16 \\
140 \cdot 43 \\
74 \cdot 83 \\
145 \cdot 51\end{array}$ & $\begin{array}{r}82 \cdot 74 \\
96.72 \\
135.75 \\
122.76 \\
136.01 \\
71 \cdot 76 \\
141.84\end{array}$ & \begin{tabular}{|r|}
79.46 \\
93.80 \\
128.07 \\
117.45 \\
132.76 \\
71.25 \\
137.94
\end{tabular} \mid & $\begin{array}{l}0.57 \\
0.87 \\
0.85 \\
0.84 \\
1.17 \\
0.77 \\
0.88\end{array}$ & $\begin{array}{r}80 \cdot 58 \\
95.51 \\
129.73 \\
119.09 \\
135.04 \\
72.76 \\
139.66\end{array}$ & $\begin{array}{r}78 \cdot 34 \\
92 \cdot 09 \\
126 \cdot 40 \\
115 \cdot 80 \\
130 \cdot 47 \\
69 \cdot 74 \\
136 \cdot 22\end{array}$ \\
\hline \multicolumn{10}{|c|}{ Lower Jaw } \\
\hline $\begin{array}{l}\mathbf{I}_{1} \\
\mathbf{I}_{2} \\
\mathbf{C} \\
\mathbf{P m}_{1} \\
\mathbf{P m}_{2} \\
\mathbf{M}_{1} \\
\mathbf{M}_{2}\end{array}$ & $\begin{array}{l}\ldots \\
\cdots \\
\cdots \\
\cdots \\
\cdots\end{array}$ & $\left|\begin{array}{r}72 \cdot 96 \\
87 \cdot 63 \\
126 \cdot 16 \\
136 \cdot 20 \\
147 \cdot 87 \\
73 \cdot 69 \\
136 \cdot 87\end{array}\right|$ & $\begin{array}{l}0.72 \\
0.71 \\
0.80 \\
0.99 \\
1.17 \\
0.79 \\
0.84\end{array}$ & \begin{tabular}{|r|}
$74 \cdot 38$ \\
$89 \cdot 01$ \\
$127 \cdot 72$ \\
$138 \cdot 14$ \\
$150 \cdot 16$ \\
$75 \cdot 24$ \\
$138 \cdot 53$
\end{tabular} & \begin{tabular}{|r|}
$71 \cdot 54$ \\
$86 \cdot 25$ \\
$124 \cdot 61$ \\
$134 \cdot 26$ \\
$145 \cdot 57$ \\
$72 \cdot 15$ \\
$135 \cdot 22$
\end{tabular} & \begin{tabular}{|r|}
$69 \cdot 22$ \\
$84 \cdot 17$ \\
$112 \cdot 90$ \\
$126 \cdot 33$ \\
$139 \cdot 62$ \\
$70 \cdot 08$ \\
$134 \cdot 15$
\end{tabular} & $\begin{array}{l}0.57 \\
0.70 \\
0.74 \\
0.94 \\
1 \cdot 17 \\
0.67 \\
0.89\end{array}$ & $\begin{array}{r}70 \cdot 35 \\
85 \cdot 55 \\
114 \cdot 34 \\
128 \cdot 18 \\
141.91 \\
71.40 \\
135.89\end{array}$ & \begin{tabular}{|r|}
68.08 \\
82.79 \\
111.45 \\
124.48 \\
137.33 \\
68.77 \\
132.40
\end{tabular} \\
\hline
\end{tabular}

sample. Thus, children from all classes of the RegistrarGeneral's (1931) socio-economic classifications are included, and in the older age groups adolescents are grouped with children who do not yet show external signs of puberty. The data have been examined to see if these factors influence the mean eruption times of the teeth.

Mean Eruption Times of Teeth in Different Social Classes.-The data were sub-classified into the social classes previously specified. Class I was combined with Class II, and Class IV with Class V. Probit computations were carried out on the data for the right lower teeth in boys. None of the differences are statistically significant, although a trend towards an earlier eruption in Classes I and II 
TABLE II.-Mean Eruption Times and Standard Errors of the Teeth in the Right Lower Jaw for Social Classes I and II Combined and for Class III in Boys*

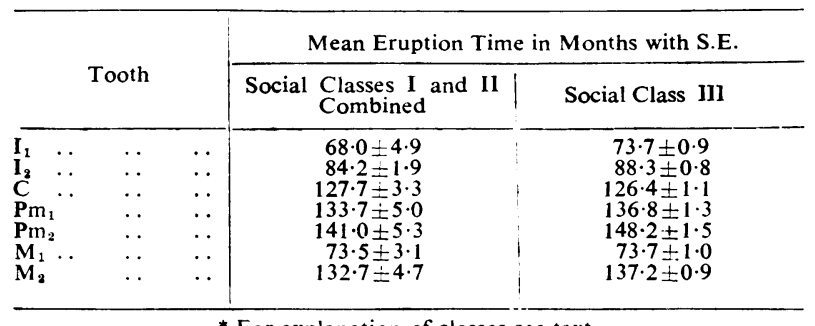

* For explanation of classes see text.

combined is apparent. The statistics for Classes I and II combined and for Class III are given in Table II. Classes IV and $\mathrm{V}$ combined follow Class III very closely. The mean difference between the classes, over all the teeth, is $3.36 \pm$ 1.13 months, a finding which indicates that the differences between the mean eruption times are important. Further analysis was unprofitable because of the small number of children in Classes I and II.

Variation in Mean Eruption Time Associated with Puberty.-The data were sub-classified into two groups: (1) those showing no onset of pubertal development; and (2) those showing obvious signs of such development. The mean eruption times were computed for the right lower $\mathrm{C}$, $\mathrm{Pm}_{1}, \mathrm{Pm}_{2}$, and $\mathbf{M}_{2}$ teeth of boys and girls, and are given in Table III. A trend towards the, earlier eruption of teeth

TABLE III.-Mean Eruption Times and Standard Errors of the Lower Right C, $\mathrm{Pm}_{1}, \mathrm{Pm}_{2}$, and $M_{2}$ Teeth in Boys and Girls With and Without the Physical Signs of Puberty

\begin{tabular}{|c|c|c|c|c|}
\hline \multirow{3}{*}{ Tooth } & \multicolumn{2}{|c|}{ Boys } & \multicolumn{2}{|c|}{ Girls } \\
\hline & \multicolumn{2}{|c|}{$\begin{array}{l}\text { Mean Eruption Times in } \\
\text { Months with S.E. }\end{array}$} & \multicolumn{2}{|c|}{$\begin{array}{l}\text { Mean Eruption Times in } \\
\text { Months with S.E. }\end{array}$} \\
\hline & $\begin{array}{c}\text { No } \\
\text { Development }\end{array}$ & $\begin{array}{c}\text { With } \\
\text { Development }\end{array}$ & $\begin{array}{c}\text { No } \\
\text { Development }\end{array}$ & $\begin{array}{c}\text { With } \\
\text { Development }\end{array}$ \\
\hline $\begin{array}{l}\mathrm{C} \\
\mathrm{Pm}_{1} \\
\mathrm{Pm}_{3} \\
\mathrm{M}_{2}\end{array}$ & $\begin{array}{l}127.7=1.3 \\
137.4=1.6 \\
148.8=1.8 \\
137.8=1.2\end{array}$ & $\begin{array}{l}123 \cdot 2 \pm 3 \cdot 7 \\
137 \cdot 6=2 \cdot 2 \\
147.8=1.9 \\
135 \cdot 3=2 \cdot 3\end{array}$ & $\begin{array}{l}113.3 \pm 0.7 \\
126.8 \pm 1 \cdot 6 \\
136.3 \pm 1 \cdot 7 \\
133.6 \pm 1.1\end{array}$ & $\begin{array}{l}108 \cdot 9 \pm 6 \cdot 6 \\
124 \cdot 1=4 \cdot 4 \\
129 \cdot 3 \pm 8 \cdot 3 \\
130 \cdot 2 \pm 2 \cdot 8\end{array}$ \\
\hline
\end{tabular}

in the pubescent group is apparent in both sexes, although the differences between the mean eruption times are not statistically significant. The mean difference between the two groups, over all the teeth, is $1.95 \pm 1.0$ months for bov's and $4.13 \pm 0.72$ months for girls : values which indicate that the differences between the mean eruption times of the groups are important. No sub-classification was made into the various stages of puberty, although it was apparent that the few boys and girls who were well advanced all had their $\mathrm{M}_{2}$ teeth, whatever their age. This observation indicates that if children are examined on several occasions during their growth the early eruption of the $\mathrm{M}_{2}$ tooth may be found to be associated with early puberty.

The effect of a possible interaction between the social and developmental classifications of the data has been ignored in making these examinations, but the findings indicate that, whilst the mean eruption times of teeth recorded in Table I

TABLE IV.-Difference in Months Between the Mean Eruption Times with the Standard Error of the Corresponding Right and Left Teeth of the Upper and Lower Jaws

\begin{tabular}{|c|c|c|c|c|c|}
\hline \multirow{2}{*}{\multicolumn{2}{|c|}{ Tooth }} & \multicolumn{2}{|c|}{ Right and Left Upper Jaw } & \multicolumn{2}{|c|}{ Right and Left Lower Jaw } \\
\hline & & Boys & Girls & Boys & Girls \\
\hline $\begin{array}{l}\mathbf{I}_{1} \\
\mathrm{I}_{2} \\
\mathbf{C} \\
\mathrm{Pm}_{1} \\
\mathrm{Pm}_{2} \\
\mathbf{M}_{1} \\
\mathbf{M}_{2}\end{array}$ & $\begin{array}{l}\ldots \\
\ldots \\
\ldots \\
\ldots \\
\ldots\end{array}$ & $\begin{array}{l}+2.09 \pm 1.41 \\
-0.37 \pm 0.95 \\
+0.70 \pm 1.48 \\
-0.34 \pm 1.52 \\
-0.56 \pm 1.58 \\
+0.66 \pm 1.15 \\
-0.02 \pm 1.26\end{array}$ & $\begin{array}{r}-0.07 \pm 0.89 \\
+0.59: 1.27 \\
-0.97: 1.27 \\
+0.99: 1.18 \\
-1.92: 1.80 \\
+0.49 \pm 1.01 \\
-0.23 \pm 1.24\end{array}$ & $\begin{array}{l}-0.71 \pm 1.08 \\
+0.18 \pm 1.03 \\
+0.12 \pm 1.14 \\
+0.88 \pm 1.44 \\
+0.31 \pm 1.64 \\
+0.49 \pm 1.02 \\
-1.45 \pm 1.30\end{array}$ & $\begin{array}{l}-0.26 \pm 0.79 \\
-0.16 \pm 1.01 \\
+0.07 \pm 1.03 \\
-0.02 \pm 1.40 \\
-0.67 \pm 1.72 \\
+1.17 \pm 0.94 \\
+1.08 \pm 1.28\end{array}$ \\
\hline
\end{tabular}

The mean eruption time of the left tooth has been subtracted from that of the right in all cases. may apply to elementary schoolchildren generally, because slight variations in the constitution of this population from place to place may be ignored, they should not serve as standards for other groups of children.

Mean Eruption Times of the Dentitions on the Right and Left Sides.-The mean eruption times have been computed for the right and left upper and lower teeth. The differences between these times are set out in Table IV. No significant difference was found between the mean eruption times of the teeth of the right and left sides of the upper and lower jaws in boys and girls.

Sexual Differences in the Mean Eruption Times.-A comparison of the mean eruption times of the teeth in the right upper and lower jaws of boys and girls is given in Table V.

TABLE V.-Differences Between the Mean Eruption Times, with Standard Errors, of the Teeth of Boys and Girls in the Right Upper and Lower Jaws, and Between the Upper and Lower Jaw's in the Same Sex

\begin{tabular}{|c|c|c|c|c|c|}
\hline \multirow{3}{*}{\multicolumn{2}{|c|}{ Tooth }} & $\begin{array}{c}\text { Right } \\
\text { Upper Jaw }\end{array}$ & $\begin{array}{c}\text { Right } \\
\text { Lower Jaw }\end{array}$ & Boys & Girls \\
\hline & & $\begin{array}{l}\text { Difference } \\
\text { Between } \\
\text { the Mean } \\
\text { Eruption } \\
\text { Times in } \\
\text { Months, } \\
\text { with S.E. }\end{array}$ & $\begin{array}{l}\text { Difference } \\
\text { Between } \\
\text { the Mean } \\
\text { Eruption } \\
\text { Times in } \\
\text { Months, } \\
\text { with S.E. }\end{array}$ & $\begin{array}{l}\text { Difference } \\
\text { Between } \\
\text { the Mean } \\
\text { Eruption } \\
\text { Times in } \\
\text { Months, } \\
\text { with S.E. }\end{array}$ & $\begin{array}{l}\text { Difference } \\
\text { Between } \\
\text { the Mean } \\
\text { Eruption } \\
\text { Times in } \\
\text { Months, } \\
\text { with S.E. }\end{array}$ \\
\hline & & Boys-Girls & Boys-Girls & Upper-Lower & Upper-Lower \\
\hline $\begin{array}{l}\mathrm{I}_{1} \\
\mathrm{I}_{2} \\
\mathrm{C} \\
\mathrm{Pm} \\
\mathrm{Pm}_{2} \\
\mathrm{M}_{1} \\
\mathrm{M}_{2}\end{array}$ & $\begin{array}{l}\ldots \\
\cdots \\
\cdots \\
\cdots \\
\cdots \\
\cdots\end{array}$ & $\begin{array}{l}+4.67 \pm 0.91 \dagger \\
+4.37 \pm 1.14 \dagger \\
+9.49 \pm 1.25 \dagger \\
+7.51 \pm 1.40 \dagger \\
+5.45 \pm 1.63 \dagger \\
+2.04 \pm 1.10 \\
+5.73 \pm 1.29 \dagger\end{array}$ & $\begin{array}{r}+3.74=0.92+ \\
+3.46=1.00+ \\
+13.26=1.09+ \\
+9.87=1.37 \\
+8.25=1.66+ \\
+3.61=1.04+ \\
+2.72=1.22 *\end{array}$ & $\begin{array}{r}+11.17 \pm 1.01+ \\
+10.54=1.03+ \\
+11.40 \pm 1.22 \dagger \\
-11.24=1.49+ \\
-9.55 \pm 1.63 \dagger \\
-0.40=1.11 \\
+6.80=1.26 \dagger\end{array}$ & $\begin{array}{r}+10.24 \pm 0.81 \dagger \\
+9.63 \pm 1.12 \\
+15.17 \pm 1.13 \\
-8.88 \pm 1.26 \\
-6.86 \pm 1.65 \\
+1.17 \pm 1.01 \\
+3.79 \pm 1.28\end{array}$ \\
\hline
\end{tabular}

In the upper jaw the mean eruption time of every tooth with the exception of the $M_{1}$ was significantly later for the boys than for the girls. In the lower jaw the mean eruption times of the teeth in boys were significantly later than those for the girls. (The level of significance of the difference in the case of the $\mathbf{M}_{2}$ tooth is only at the $5 \%$ level of probability.) This finding confirms the previous observations made by Ainsworth (1925) and Leslie (1951).

Comparison of the Mean Eruption Times of the Corresponding Upper and Lower Teeth.-The differences between the mean eruption times for boys and girls are given in Table V. It is apparent that the mean eruption times of the teeth in the upper jaw are later for both sexes, with the following exceptions:-Boys: The lower $\mathrm{Pm}_{1}$ and $\mathrm{Pm}_{2}$ teeth erupt about 11 and 10 months respectively after the corresponding upper teeth (a difference statistically significant at the $1 \%$ level of probability). The difference between the upper and lower $\mathbf{M}_{1}$ teeth was not significant. Girls: The lower $\mathrm{Pm}_{1}$ and $\mathrm{Pm}_{2}$ teeth erupt a matter of nine and seven months respectively after the upper teeth (both differences are statistically significant at the $1 \%$ level of probability). The difference between the mean eruption times of the upper and lower $M_{1}$ teeth was not significant. The observation that the mean eruption time of the lower $\mathrm{Pm}_{1}$ tooth is significantly later than that of the upper for boys and girls, whereas generally the teeth in the upper jaw are later than those in the lower jaw, has also been made in previous surveys.

Sequence of the Mean Eruption Times.-The order of eruption of the teeth determined from the mean eruption times is set out in Table VI. It is found that the order is the same in boys and girls, but that the order is different in the upper and lower jaws. The eruption times of the $I_{1}$ and $\mathbf{M}_{1}$ teeth and the $\mathbf{P m}_{1}, \mathrm{Pm}_{2}$, and $\mathbf{M}_{2}$ teeth are so similar that sampling variation can give rise to a different order of eruption in a proportion of determinations. The order of eruption of the teeth has been determined from the mean eruption times found in some recent surveys, and the results are included in Table VI. It is apparent that the 
TABLE VI.-Order of Eruption of the Permanent Teeth in Several Countries, as Determined from the Mean Eruption Times

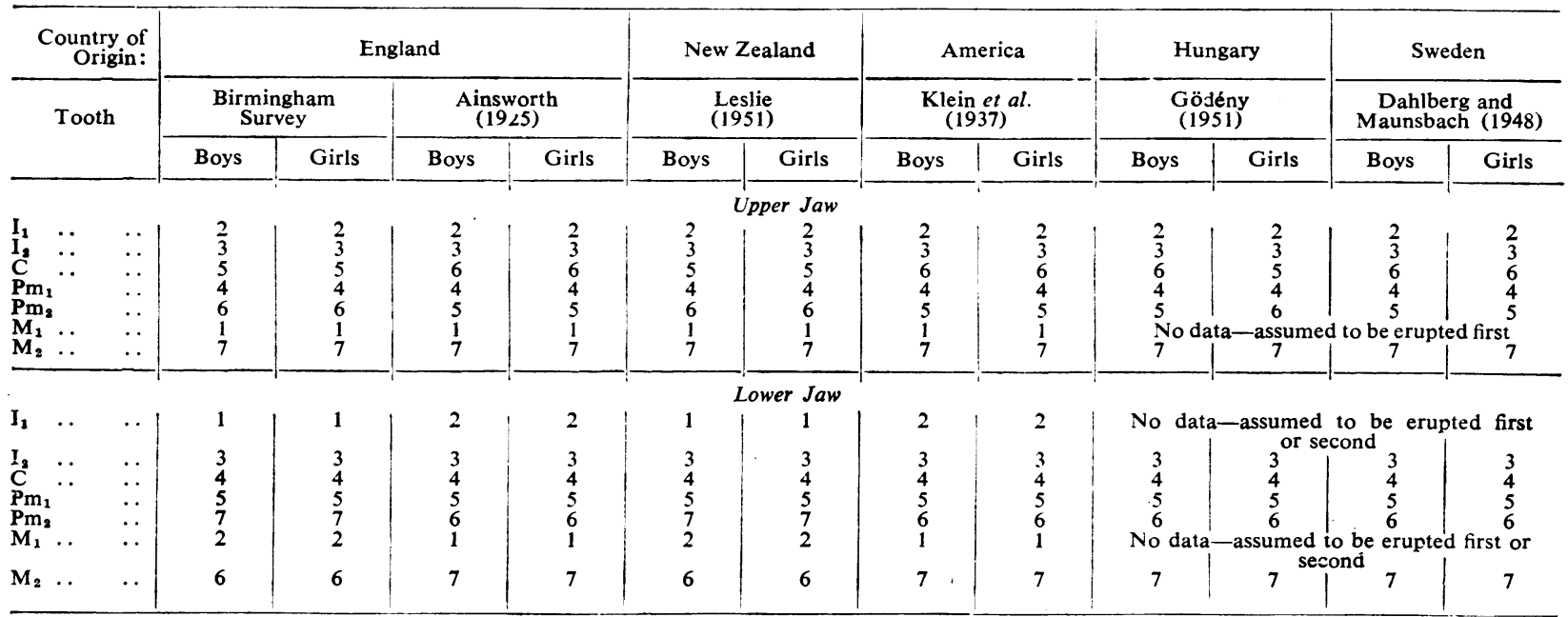

anticipated variations in the order resulting from sampling variations have been found, but, apart from this, the order of eruption is the same in each survey.

\section{Discussion}

Although the statistical significance of the differences cannot be assessed satisfactorily, comparison of the mean times of eruption of teeth found in this survey with those reported by Ainsworth (1925) suggests that to-day the mean eruption times of teeth are, with the following exceptions, a few months earlier in each sex : the upper and lower $\mathrm{Pm}_{2}$ teeth in both sexes, the upper and lower $\mathrm{Pm}_{1}$ teeth in boys, the lower $\mathrm{Pm}_{1}$ teeth in girls, which are all a few months later than they were 25 years ago. Except in the case of the premolar teeth, the mean eruption times found in 1947-8 also tend to be a few months sooner than those which are indicated by the data for English children published by James and Pitts (1912).

These comparisons suggest that there has been a tendency for the mean eruption times of all teeth, except the premolars, to become earlier in this country during the past 40 years. The later eruption of the premolar teeth may be attributable to a fall in the rate of extraction of the preceding temporary molar teeth, and may be a change towards a more normal time of eruption (see Leslie, 1951). The indications that mean eruption times of teeth, other than the premolars, may be earlier in children from a better socio-economic environment, which are provided by the present survey and which are supported by the observations of Hellman (1923) on the incisor teeth, suggest that this trend may reflect a progressive improvement in the socioeconomic condition of the nation. The conclusions Hellman drew from his data were based mainly on the findings for the premolar teeth, and differ from ours on this account.

The likelihood that socio-economic and general physical status have an influence on the time of eruption is given further substance by the observations that children who show physical signs of puberty tend to have earlier mean eruption times than children who are still prepubertal.

The mean eruption times of teeth as determined in the Birmingham Survey appear to be a few months in advance of those found by Leslie (1951) for New Zealand children. The method by which his statistics are computed introduces errors due to rounding, and thus makes the statistical significance of any detailed comparison with our data uncertain, but the differences would probably be statistically significant for about half of the teeth. The mean eruption times of the teeth of Birmingham children tend to be earlier than those of other European children, except for the lower premolar teeth, and the differences are slightly greater than they are in the New Zealand data (Dahlberg and Mauns- bach, 1948 ; Gödény, 1951). These findings suggest that the physical development of British children to-day, in so far as it is reflected in changes in the mean eruption times of teeth, is slightly in advance of that of other children of European stock, and those from New Zealand, about which we have information.

\section{Summary}

The mean times of eruption of human teeth have been computed from observations on 1,427 boys and 1,365 girls aged 5 to 13 years.

The mean times of eruption of teeth of children who are either of a superior socio-economic group or are pubescent tend to be earlier than those in other children.

The mean times of eruption of the corresponding right and left teeth do not differ significantly in either the upper or the lower jaws.

The mean times of eruption of the teeth of boys are, with the exception of the upper $M_{1}$ teeth, later than those of girls.

The mean times of eruption of teeth in the upper jaw are later than those in the lower jaw, except for the Pms and $\mathrm{Pm}_{2}$ teeth, which are earlier, and the $\mathrm{M}_{1}$ teeth, which do not differ significantly.

The order of eruption of the teeth determined from mean eruption times is the same, within the limits of sampling variation, as that found in other stocks of European origin.

This work would have been impossible without the ready help of the City of Birmingham Educàtion Committee and its administrative, medical, and teaching staffs, too numerous to mention individually. We gratefully acknowledge our debt to them, to the Medical Research Council for the receipt of a grant, and to Professor S. Zuckerman and Mr. M. J. R. Healy for much assistance and advice.

\section{REFERENCES}

Ainsworth, N. J. (1925). Spec. Rep. Ser. med. Res. Coun., Lond.. No. 97 Black, A. N. (1950), Biometrika, 37, 158.

Dahlberg, G., and Maunsbach, A. B. (1948), Acta genet.. Basel. 1. 77. Finney, D. J. (1947). Probit Analysis. Cambridge.

Gödény, E. (1951), Acta genet., Basel, 2, 331. Culotta, C. J. (1942). Monogr. Soc. Res. Child. Dev., 7, No. 3, Serial No. 33

Hellman, M. (1923). Dent. Cosm., 65, 34.

James, W. W., and Pitts, A. T. (1912). Proc. roy. Soc. Med., 5 (Odont. Sect.), 80

Klein, H., Palmer, C. E., and Kramer, M. (1937). Growth, 1, 385.

Leslie, G. H. (1951). A Biometrical Study of the Eruption of the Permanent Dentition of New Zealand Children. Government Printing Office. Wellington.

Registrar-General (1931). Classification of Occupations. H.M.S.O., London. Schultz, A. H. (1934). Amer. J. phys. Anthrop., 19, 489.

Tocher. K. D. (1949) Biometrika, 36, 9. 